\section{Commentary: Bicuspid aortic valve consensus or quandary?}

\section{Thomas G. Gleason, MD}

In a consensus, 51 physicians and scientists have written a comprehensive document aimed at establishing a uniform nomenclature and classification scheme for bicuspid aortic valve (BAV) and its associated aortopathy_charging the cardiovascular community to use and adopt their new derivation of terms. ${ }^{1}$ Notwithstanding its length, the manuscript serves as an outstanding review of current issues revolving around "the BAV condition" extending well beyond nosology, reflecting extensively on treatment indications, diagnostic methods, treatment strategies, and genetics. Much of the commentary, particularly on techniques of echocardiographic, cardiac magnetic resonance, and gated computed tomographic imaging, is both informative and relevant to the imaging of the aortic valve/root regardless of valve morphology. It is certainly reasonable to consider the establishment of a uniform BAV language for clinicians and scientists alike to better align distinct observations (clinical, embryologic, pathologic, or biological) with morphologic characteristics across disciplines and to both prevent confusion and engender greater knowledge.

Naturally, there is a desire to compartmentalize and codify diseases to create the perception of order and understanding. In some cases, establishing such "languages" has been instrumental to marching progress-as seen in the oncologic world. With BAV, although it is true that many classification schemes have been proposed, none completely comprehensive, and none universally accepted, the heterogeneity in perspective may be justified, even healthy toward fueling ongoing discourse and the pursuit of the yet unknown. Despite the authors' allusion that a numerical system of nomenclature is less "simple-butcomprehensive" than one "based on the English language,"

\footnotetext{
From the Division of Cardiac Surgery, Brigham \& Women's Hospital, Boston, Mass. Disclosures: Dr Gleason serves on a Medical Advisory Board for Abbott.

The Journal policy requires editors and reviewers to disclose conflicts of interest and to decline handling or reviewing manuscripts for which they may have a conflict of interest. The editors and reviewers of this article have no conflicts of interest.

Received for publication Dec 14, 2020; revisions received Dec 14, 2020; accepted for publication Dec 15, 2020.

Address for reprints: Thomas G. Gleason, MD, Division of Cardiac Surgery, Brigham \& Women's Hospital, 75 Francis St, Boston, MA 02115 (E-mail: tgleason@bwh. harvard.edu).

J Thorac Cardiovasc Surg 2021;162:801-2

$0022-5223 / \$ 36.00$

Copyright (c) 2020 by The American Association for Thoracic Surgery

https://doi.org/10.1016/j.jtcvs.2020.12.067
}

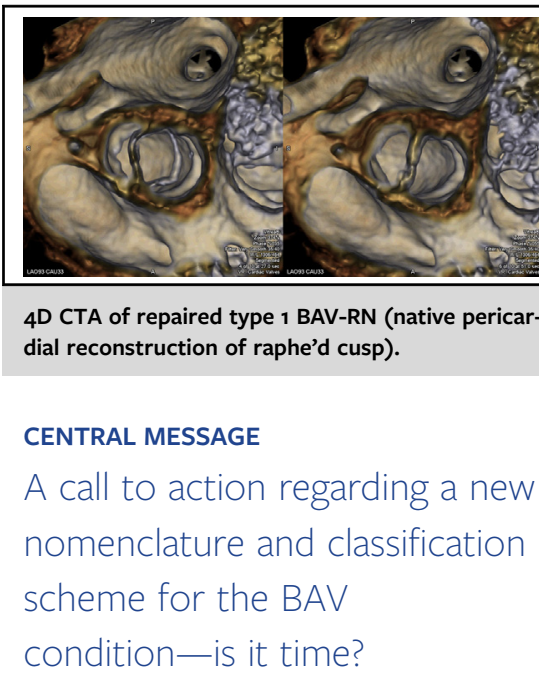

the most widely used Sievers classification scheme ${ }^{2}$ achieved the same goal: simple-but-comprehensive, relying on the observation (by imaging or intraoperatively) of reliably identifiable raphes. The premise of the new "fused BAV" moniker may be flawed in this respect.

In fact, what's clear from the work of many, and perhaps best highlighted by a recent review by the animal biology group of Fernandez in Spain, ${ }^{3}$ is that we lack (based predominantly on rodent studies) an understanding of the embryology of BAV. The "fused BAV" nomenclature concept implies that a unique "fusion" of cusps occurred during its development. What's confusing about this is that fusion of the conotruncal ridges (CRs) is fundamental to the development of all aortic valves, regardless of morphology. Aortic valve development, or maldevelopment in the case of BAV, occurs across a broad continuum, which appears to be alterable across many of the embryologic stages yet can phenotypically manifest in similar ways. Aberrant mechanisms in endocardial fusion formation, outflow tract septation, and valve cushion excavation, in rodents, each can give rise to various forms of BAV resulting from deficient or aberrant endothelial-to-mesenchymal cell transition, neural crest cell migration, or focal mesenchymal cell proliferation in the valve cushions creating that broad continuum. ${ }^{3}$ Notably, when CR fusion extends more dorsally than normal in the hamster, the right-left BAV morphotype can form, but no such aberration in CR fusion occurs during the formation of rodent right-noncoronary $\mathrm{BAVs}^{3-7}$; generally, cusp fusion as implied is not actually occurring.

With respect to BAV aortopathy, there is certainly value in embracing a universal language to describe aortic dilatation patterns and perhaps shapes in the context of BAV. However, simple descriptions of that which clinicians see, 
ie, describing the extent of dilatation, also seem reasonable, given that dilatation patterns do not correlate well with valve morphotype (except perhaps in the case of the R-N morphotype). Moreover, while it is true that the term aneurysm often carries a bad connotation and it is also true that the term is often misused clinically in lieu of "dilatation," it seems somewhat arbitrary and unnecessary to abandon the term altogether, given its longstanding use in the literature dating back to Galen's description circa 180 AD. Embracing qualitatively descriptive terms is certainly appropriate, as is an emphasis of using "aneurysm" only when meeting criteria for such a distinction (eg, a caliber $150 \%$ of normal) — consistent with historical precedent.

In summary, this document provides us with an excellent perspective on the concepts that embody the "BAV condition," but it seems we lack adequate insight to justify generating a new, and universal, classification schema beyond those already in use. Despite our desire for order, is this call for change really evidence-based?

Perhaps we should circle back to Gershwin and Gershwin: "you like tomato, I like tomatoe...."

\section{References}

1. Michelena HI, Della Corte A, Evangelista A, Maleszewski JJ, Edwards WD, Roman MJ, et al. International consensus statement on nomenclature and classification of the congenital bicuspid aortic valve and its aortopathy, for clinical, surgical, interventional and research purposes. J Thorac Cardiovasc Surg. 2021;162:e383-414

2. Sievers HH, Schmidtke C. A classification system for the bicuspid aortic valve from 304 surgical specimens. J Thorac Cardiovasc Surg. 2007;133:1226-33.

3. Soto-Navarrete MT, Lopez-Unzu MA, Duran AC, Fernandez B. Embryonic development of bicuspid aortic valves. Prog Cardiovasc Dis. 2020;63:407-18.

4. Fernandez B, Duran AC, Fernandez-Gallego T, Fernandez MC, Such M, Arque JM, et al. Bicuspid aortic valves with different spatial orientations of the leaflets are distinct etiological entities. J Am Coll Cardiol. 2009;54:2312-8.

5. Fernandez B, Fernandez MC, Duran AC, Lopez D, Martire A, Sans-Coma V. Anatomy and formation of congenital bicuspid and quadricuspid pulmonary valves in Syrian hamsters. Anat Rec. 1998;250:70-9.

6. Sans-Coma V, Fernandez B, Duran AC, Thiene G, Arque JM, Munoz-Chapuli R, et al. Fusion of valve cushions as a key factor in the formation of congenital bicuspid aortic valves in Syrian hamsters. Anat Rec. 1996;244:490-8.

7. Blaser MC, Wei K, Adams RLE, Zhou YQ, Caruso LL, Mirzaei Z, et al. Deficiency of natriuretic peptide receptor 2 promotes bicuspid aortic valves, aortic valve disease, left ventricular dysfunction, and ascending aortic dilatations in mice. Circ Res. 2018;122:405-16.

8. Gershwin G, Gershwin I. Let's Call the Whole Thing Off. Score 1543. New York: Vocal Popular Sheet Music Collection; 1937. Available at: https://digi talcommons.library.umaine.edu/mmb-vp-copyright/1543/. Accessed January 6, 2021. 